\title{
Reflexões sobre a estrutura lógico-formal da norma jurídica ante a sanção premial
}

\author{
Reflections on the formal logic structure of Legal \\ Norm before the Rewarding Sanction
}

\author{
Arnaldo Vasconcelos* \\ Guilherme Dourado Aragão Sá Araujo*
}

\section{Resumo}

Cuida da alocação da sanção premial na estrutura lógico-formal da norma jurídica. Seu objetivo geral é identificar, na estrutura formal da norma, o lugar dos tipos de sanção, seja ela punitiva, em condutas aquém do ideal prescrito, seja ela premial, no caso de condutas além do ideal prescrito. Nesse sentido, torna-se necessário, em primeiro lugar, realizar incursão no plano metafísico a fim de despir a norma jurídica de seu conteúdo semântico para revelar sua essência lógico-formal. Após abstração do plano físico dos conteúdos ao plano metafísico das formas, torna-se necessária a elucidação dos fundamentos da lógica formal para melhor compreensão da estrutura da norma jurídica. Ao manejar esses mesmos fundamentos da lógica formal, perceber-se-á um equívoco fundamental na mentalidade jurídica tradicional que consiste em verdadeira falha no desdobramento lógico do axioma da identidade. Somente com a correção desse equívoco pode ser revelado o verdadeiro lugar da sanção premial na estrutura lógica da norma jurídica.

Palavras-chave: Teoria da Norma. Lógica Jurídica. Sanção Premial. Epistemologia Jurídica.

* Doutorado em Direito pela Universidade Federal de Pernambuco (2002); Mestrado em Direito Público pela Universidade Federal do Rio de Janeiro (1977) e Professor titular da Universidade de Fortaleza; Graduação e licenciatura em Filosofia pela Faculdade Católica de Filosofia de Fortaleza (1966); Graduação em Ciências Jurídicas e Sociais pela Universidade Federal do Ceará (1965); Fortaleza - CE - Brasil. E-mail: arnaldo@unifor.br.

** Mestre em Direito Constitucional pela Universidade de Fortaleza. Professor de Direito Tributário e Direito Eleitoral da Unicatólica de Quixadá. Advogado. Fortaleza-CE - Brasil. E-mail: gdourado@ edu.unifor.br. 


\section{Abstract}

It deals with the problematic placement of the rewarding sanction in the logicalformal structure of the legal norm. Its overall objective is to identify, in the formal structure of the norm, the place of the types of sanctions, whether it is punitive in the case of behaviors below the ideal prescribed, whether it is rewarding in behaviors beyond the ideal prescribed. In this path, it becomes necessary, first, perform an incursion in the metaphysical plane in order to divest the legal norm from its semantic content to reveal its formal logic essence. After abstraction from the physical plane of contents to the metaphysical plane of forms, it becomes necessary the elucidation of the formal logic fundamentals for better understanding of the legal norm structure. When handling these same fundamentals of formal logic, it will be noticed a fundamental misconception in the traditional legal mindset which consists of a true failure in the logical deployment of the identity axiom. Only with the correction of this error, can the true place of the rewarding sanction in the logical structure of the legal norm be revealed.

Keywords: Theory of Norm. Legal Logic. Rewarding Sanction. Law Epistemology.

\section{Introdução}

Durante pelo menos os últimos dois séculos, prepondera a ideia de que a coação - uso da força física - constituiria elemento inerente à essência do Direito e, em virtude das características metafísicas próprias da essencialidade do ser, a coação seria, por via de consequência, uma entidade perene no direito.

Qualquer ínfima manifestação de uma relação jurídica estaria, portanto, sob a permanente égide da ameaça do uso da força. Essa concepção, fortemente enraizada graças à difusão de sua ideologia, exclui qualquer possibilidade de existência de alguma relação jurídica na qual não haja coação.

Em meio a esse contexto, este estudo será direcionado a três eixos principais. Em primeiro lugar, serão delineados os basilares 
epistemológicos da distinção entre física e metafísica, para que se perceba quais os pressupostos e quais as consequências de se considerar algum elemento como essencial do ser ou existencial do dever-ser. Será demonstrada a necessidade de se abstrair do plano físico da matéria ao plano metafísico das formas para se conhecer a essência de algo. Somente neste plano é que o ser formal, despido de seu conteúdo material, poderá ter reconhecida sua verdadeira essência.

Em segundo lugar, dedica-se ao aprofundamento, no plano metafísico das formas, das estruturas lógicas componentes do casulo formal que serve à veiculação de todas as mais diversas linguagens quando esse casulo é preenchido de conteúdo semântico. Mediante o estudo das formas lógicas e dessa sobrelinguagem (esqueleto da linguagem despida de seu conteúdo), que são pressupostos à linguagem jurídica, pode-se partir para a terceira parte do ensaio, que cuida da identificação da verdadeira essência do Direito ante a impossibilidade de ter a coação jurídica perante a existência da sanção premial.

Dessa forma, a se desenvolver o estudo, percebe-se que a coação não pode fazer parte da essência do Direito pelo simples motivo da existência de relações jurídicas que surgem e se exaurem sem qualquer relação com o uso força física ou com a coação.

Ao se verificar pelo menos uma existência em que não haja esse recurso coativo, desfaz-se a ideia de que essa coação está na essência do ser. Cogitar o contrário seria erroneamente aceitar um "ser" despido de sua essência ou, em outras palavras, seria cogitar em um "ser" que não "é".

Por fim, o estudo da teoria da norma jurídica em seu aspecto lógico-formal (metafísico, do plano da essência) revelará qual o lugar da sanção premial na perinorma, bem como a harmonização da possibilidade de coexistência, tanto de sanções punitivas, voltadas a desestimular condutas aquém do ideal prescrito na endonorma, como de sanções premiais, destinadas a estimular condutas além do ideal prescrito na endonorma. 


\section{A importância da conceituação para o conhecimento}

Em meio aos turvos limites entre a Filosofia e a Ciência está o objeto de estudo da Epistemologia, disciplina que se ocupa da Teoria do Conhecimento em si e de seus respectivos processos. Ao assumir esse pressuposto, percebe-se que a Epistemologia está intimamente relacionada com os problemas de categorização do conhecimento ao agir como verdadeiro elo entre o sensível e o inteligível, entre existência e essência (SANTOS, 1958).

Seguindo esse raciocínio, ao se verificar a importância da categorização à epistemologia, percebe-se, por consequência, a igualmente íntima relação entre a Teoria do Conhecimento e os problemas de conceituação, uma vez que delimitar um conceito é também uma forma de categorizar algo de acordo com as propriedades conotadas pelo conceito (COSTA, 2009).

Diz-se, em especial, desde Immanuel Kant (2001), precisamente por meio de seu criticismo, que o estudo do saber e da realidade não poderia ser levado a cabo sem antes haver uma delimitação das possibilidades do saber, e, portanto, dos limites da cognição de um objeto por um sujeito cognoscente.

Embora essa concepção seja aceitável em certos termos (e sua consequência prática seja perseguida no decorrer deste ensaio), devese rememorar a lição de Xavier Zubiri (2011, p. LII) ao ensinar que "se alguém que quisesse abrir uma porta passasse horas estudando o movimento dos músculos de sua mão; provavelmente não chegaria nunca a abrir a porta".

Precisamente, buscar-se-á, neste escólio acadêmico, delimitar conceitos acerca de temáticas fundamentais à Ciência do Direito, mas sempre ciente de que a posição adotada não necessariamente revelará um consenso científico ou uma "verdade absoluta".

O contexto tende, portanto, a um equilíbrio diante da busca da cognição do objeto pelo sujeito cognoscente, com a Ciência, de antemão, 
de que não é possível dominar um conhecimento absoluto da verdade, mas que tampouco não possa haver nenhum conhecimento sobre ela.

Para que se possa inteligir o que é o objeto de estudo, é preciso chegar à essência do ser. Esse desafio de regredir à essência do objeto é uma necessidade lógica da realidade. As coisas que existem e são sensíveis estão impregnadas de acidentes, estes acrescidos à sua essência formal, de modo que a mera percepção do que existe não é capaz de proporcionar a distinção entre o que é a essência do ser e o que são os acidentes do existir.

Apenas por meio da intelecção, é possível abstrair-se do mundo físico das coisas que existem, com suas mesclas de essência e acidentes incorporados, para o mundo metafísico das coisas que são, onde se pode dar início ao conhecimento da essência dos objetos da cognição.

\section{Problemas terminológicos e os limites da linguagem}

Os limites da cognição encontram-se de certa forma relacionados com os lindes da linguagem. Embora se entenda que o pensamento está, na verdade, acima da linguagem (MAGALHÃES FILHO, 2015), admite-se que esta não deixa de exercer forte influência e, de certa forma, limitar aquele.

Por certo, qualquer processo de conhecimento exige o comprometimento de seus estudiosos em relação à semântica de seus conceitos. Isso porque delimitação de conceitos necessariamente envolve um problema terminológico e linguístico. Foi por essa razão que Ludwig Wittgenstein (1968) afirmou, de forma um tanto exagerada, que, em grande parte, os problemas filosóficos seriam, na verdade, questões de linguagem.

Embora não se possa adotar esse entendimento de forma absoluta, é possível atribuir-Ihe certa validade, sobretudo quanto aos problemas de semântica e de conceituação de objetos cognoscíveis. "Não é, pois, de 
admirar que os mais profundos problemas não constituam propriamente problemas." (WITTGENSTEIN, 1968, p. 70).

Conquanto seja impreciso endossar arbitrariamente a concepção do giro linguístico de que todos os problemas filosóficos são, no fundo, problemas de linguagem, por certo, alguns o são. Alguns dos ditos problemas podem ser, na verdade, apenas pseudoproblemas, cuja obscuridade envolve, sim, de uma forma ou de outra, um problema de linguagem.

É de fundamental importância a utilização de conceitos robustos para o desenvolvimento de qualquer pesquisa científica ou filosófica, especialmente porque as conclusões dependem essencialmente dos pressupostos adotados. Desse modo, a ciência ideal seria aquela formada exclusivamente por termos unívocos, que teriam cada um deles apenas um significado. Essa condição, entretanto, exatamente por ser "ideal", é praticamente impossível de se verificar na prática (ROSS, 2000).

O resultado da pluralidade de significados possíveis para um mesmo termo, como, por exemplo, "sanção" ou "norma jurídica", é que, de qualquer estudo mais aprofundado, se torna exigível, primeiramente, a individualização de qual dos vários significados possíveis a estes termos será o adotado no decorrer dos trabalhos.

As contradições do mundo da existência se revelam, na linguagem, por meio da vagueza e ambiguidade de seus termos. Para se esquivar desses problemas, torna-se necessário partir a um plano superior ao da linguagem, um plano de termos unívocos. Essa transcendência se dá pelo processo de formalização da linguagem em direção ao plano das formas e da lógica. É esse o plano da metafísica e da sobrelinguagem, como será abordado a seguir.

\section{Necessidade de incursão na lógica jurídica formal}

Ase reconhecer o fato de que a Ciência se ocupa do mundo sensível, uma vez que se fundamenta na demonstração e na experimentação de 
fatos, se reconhece, imediatamente, um limite ao saber científico. Admitir tais estremas ao objeto da Ciência, por sua vez, é aceitar a existência de algo além, que escapa à metodologia do sensível e do experimentável. Uma vez que os limites do sensível são os limites da física, aquilo que Ihe transborda em direção ao além é a metafísica (SANTOS, 1958).

O mundo metafísico, portanto, é aquele além dos sentidos, o qual somente se alcança por meio da intelecção, da capacidade de sobressairse dos limites sensoriais para explorar a razão e a Filosofia. É que "o conhecimento científico não atinge essas regiões. Por isso, no Direito, a Ciência há de compor-se com a Filosofia [...]." (VASCONCELOS, 2006, p. 243).

Precisamente ao adentrar o campo da Filosofia, encontrará o sujeito o domínio da lógica formal, pois está situada nesse mesmo campo dos objetos ideais. Como leciona Paulo de Barros Carvalho (2013, p. 68), "esse domínio é o universo das formas lógicas, situado na região ôntica dos objetos ideais, que, portanto, não têm existência concreta, real $[\ldots]$ ".

Situada nesse plano superior, a lógica formal pode ser atingida mediante a intelecção, com precedência em qualquer área conhecimento científico, inclusive na Ciência do Direito, onde quer que haja manifestação ínfima de linguagem, isto precisamente porque a lógica "formal" ocupa, a rigor da redundância terminológica, o plano das "formas", do ser ôntico, metafísico, e atua como sobrelinguagem (ou metalinguagem, linguagem formalizada), de modo que sua validade formal se superpõe aos conteúdos eventualmente veiculados:

Considerada a premissa de que o direito situa-se na região ôntica dos objetos culturais, a lógica o encontrará como um autêntico cosmos para dele organizar o seu material ontológico, constituindo verdadeiro sistema formalizado de sobrelinguagem. No entanto, fica a advertência: a lógica não altera o ordenamento jurídico, mas o descreve em linguagem formalizada, transformando o objeto cultural, que é o direito positivo, em objetos ideais, próprios das Ciências Lógicas. Constitui assim a ampliação dos horizontes culturais existentes. (CARVALHO, 2013, p. 69). 
Enquanto a linguagem pertence ao mundo deôntico do dever-ser, essa dita sobrelinguagem (metalinguagem) faz parte do mundo ôntico do ser. É uma chamada linguagem formalizada, esvaziada de seu conteúdo, para que apenas permaneça seu esqueleto, a estrutura lógica comum aos tipos de linguagem, independentemente de seus conteúdos específicos.

A sobrelinguagem (ou metalinguagem) é composta de termos unívocos, com apenas um significado, e não transporta informações de conteúdo. Pode-se atingi-la pelo processo de "formalização", segundo o qual busca o intérprete, na linguagem convencional, a estrutura lógicoformal que corresponde à sobrelinguagem.

A lógica formal constitui sobrelinguagem capaz de veicular a própria linguagem jurídica em si. Exatamente por ser "formal", a lógica não veicula, em sua sobrelinguagem, qualquer conteúdo. No caso da lógica jurídica, não há preocupação com o teor de suas proposições normativas. Seja esse conteúdo justo ou injusto, positivo ou negativo, a lógica formal apenas revela a coerência terminante das proposições, porém jamais permite que dela se possa extrair um julgamento de valor quanto ao seu conteúdo.

Essa metalinguagem apenas expressa a estrutura formal de toda e qualquer linguagem. Seja a linguagem da Matemática, da Física, da Biologia ou do Direito, qualquer delas, independentemente de seu conteúdo, é expressa com uma forma lógica, sendo a essência da linguagem (VILANOVA, 1997).

A lógica formal e suas estruturas proposicionais são - reitera-se - meras formas, casulos vazios de conteúdo. Proposições com teores diversos, como "Pedro é loiro" ou "o tigre é feroz", possuem ambas a mesma estrutura formal. Na verdade, os conteúdos podem até ser paradoxais, como na seguinte proposição complexa: "se o Sol é quente, então o Sol é frio”. Essa proposição está em consonância com a lógica da metalinguagem, pois, embora seu conteúdo seja contraditório, este teor em nada afeta a estrutura formal (ALVES, 2005). 


\section{Estruturas e operadores lógicos}

A lógica é uma sobrelinguagem (ou metalinguagem) formal, constituída por signos próprios que lhe conferem peculiar precisão, desconhecida pela quase totalidade das linguagens em curso, pois se ordena mediante vocábulos unívocos, fato impeditivo da ocorrência de ambiguidade de seus termos, o que é uma das principais dificuldades terminológicas das Ciências em geral (ALVES, 2005). Nesse momento, torna-se necessária uma incursão pelo tema das proposições e dos operadores lógicos para melhor compreensão da estrutura lógico-formal da norma jurídica.

Uma proposição lógica é constituída por signos constantes e signos variáveis. Aqueles que representam formalmente uma informação da linguagem convencional são variáveis, enquanto os constantes são aqueles signos que conectam os variáveis, proporcionando-lhes relações de negação, conjunção, disjunção ou condição.

Os signos variáveis são convencionalmente representados por letras minúsculas do alfabeto, como, por exemplo, a, b, c, ... p, q, r, s, ... (CARVALHO, 2013). Embora se tenha preferência pelas letras do final do alfabeto e por minúsculas, podem ser utilizadas, por exemplo, letras que remetam à informação da linguagem que se busca formalizar na lógica. Por exemplo, um fato ou uma hipótese descrita podem ser representados pelas letras $\mathrm{F}, \mathrm{H}$ ou $\mathrm{D}$, ao passo que uma consequência prescrita pode ter como representação as letras $C$ ou $P$. É, pois, uma sobrelinguagem, uma linguagem formalizada, esvaída de seu conteúdo.

Os signos constantes, ao seu tempo, são seis, determinados conforme a relação que se queira representar. O primeiro signo simboliza

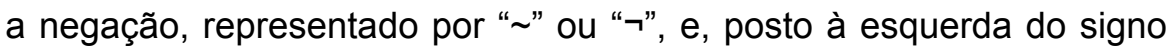
variável, inverte-lhe o sentido. Na seguinte proposição simples, tomando C por "o céu é azul", C representaria "o céu não é azul". Na negação, o que é deixa de ser e o que não é passa a ser.

O segundo constante é o conjuntor, representado por "e", que exprime relação aditiva entre duas proposições simples, e, exatamente 
por isso, é lido como a conjunção "e". Na seguinte proposição complexa A e $\mathrm{B}$ (o elemento à esquerda do operador lógico "e" é chamado prótase, e o à direita é chamado apódose), tomando A por "o fogo é quente" e B por "perdi minhas chaves", a proposição é lida como "o fogo é quente e perdi minhas chaves" (note-se que é desnecessária a coerência quanto ao conteúdo das proposições, como abordado anteriormente).

O terceiro signo constante é o disjuntor inclusivo que deve ser lido como: "ou... ou ambos". Exprime a ideia de que qualquer uma das proposições simples que conecta pode ocorrer de forma isolada, ou ambas, simultaneamente. No seguinte exemplo: Pedrinho está com sua mãe no supermercado e ela lhe diz "levarei bolo ou levarei doce de leite. Pedrinho, garoto astuto e grande conhecedor da lógica, pega ambas as guloseimas e explica a sua mãe que, segundo o cálculo proposicional do disjuntor inclusivo, admite-se a ocorrência simultânea de ambas as proposições expostas.

O quarto constante é o disjuntor exclusivo que, ao contrário do anterior, não admite ocorrência de ambas as proposições simultaneamente. Deve ser lido da seguinte forma: "ou... mas não ambos". O exemplo: "comerei lasanha ou comerei pizza, mas não ambas" é uma disjunção exclusiva.

O quinto signo constante é chamado condicional. Lido da seguinte forma: "se..., então...". Exprime uma condição, uma relação de dever-ser entre ambas as proposições simples. A primeira é chamada condicionante e a segunda é condicionada, de modo que, uma vez ocorrida a primeira, a segunda, necessariamente, também ocorrerá. Se é dito "se fizer Sol, então irei à praia", caso ocorra "Sol", então também ocorrerá "Praia". A relação é a seguinte: se ocorrer o condicionante, então ocorrerá o condicionado, mas a recíproca não é verdadeira.

O sexto e último signo constante é o chamado bicondicional. Semelhante ao anterior, este se diferencia por impor a ambas as proposições uma condição recíproca, de modo que as duas somente podem ocorrer simultaneamente, jamais isoladas. Lido da seguinte forma: “... se e somente se..... Esse operador pode ser exemplificado pela 
seguinte proposição: "comerei fora se e somente se não tiver comida em casa". Sucedendo a primeira, necessariamente ocorrerá a segunda, e, se aconteceu a segunda, é porque necessariamente ocorrera a primeira. Ambas as proposições são mutuamente condicionantes.

Desses operadores lógicos, os de maior destaque para a teoria da norma jurídica são o condicional (dever-ser "se... então...") e o disjuntor inclusivo ("ou... ou ambos"). O primeiro emite um juízo hipotético-condicional, caracterizado pela previsão de uma hipótese e de uma consequência, enquanto o segundo emite um juízo disjuntivo, caracterizado pela delimitação de duas situações não excludentes que podem ser verificadas de forma isolada ou simultânea.

\section{Teoria da norma jurídica}

A delimitação de um problema, em qualquer área do conhecimento, envolve intrinsecamente uma delimitação de conceitos. Embora não seja de grande utilidade prática a infindável e inócua discussão sobre especialíssimas delimitações conceituais, igualmente não o é a ignorância de elementos essenciais aos mesmos.

Para delimitar a problemática quanto à natureza de uma norma jurídica, deve-se atentar para algumas dificuldades terminológicas. A principal delas é, essencialmente, definir o que seria uma norma jurídica, uma vez que os pressupostos adotados por qualquer estudo invariavelmente influenciam nas conclusões deste e, estando aqueles pressupostos equivocados, igualmente estarão suas conclusões.

Uma vez que o conceito de norma jurídica depende fortemente de variáveis terminológicas, segundo concepções doutrinárias, deve-se atentar para a razão de que esse escrito não tem a pretensão de exaurir a temática, como se mais conclusões não pudessem ser verificadas com base em outros pressupostos adotados.

A primeira dificuldade do problema debatido trata da delimitação do conceito de norma jurídica. Todas as áreas do conhecimento 
passíveis de intelecção possuem um ou alguns elementos nucleicos ou fundamentais, cuja delimitação é quase sempre problemática.

Essa preocupação em delimitar os conceitos fundamentais de cada área do saber guarda indubitável correlação com a filosofia présocrática e sua busca pelo descobrimento do elemento primordial da matéria (arqué). Mesmo após o desenvolvimento das mais diversas teorias sobre qual seria o elemento primordial das coisas, tudo o que se pode saber é mera "verdade atual" (SANTOS, 1958), um conceito que, para os contemporâneos, reflete seu entendimento hodierno, mas que não necessariamente corresponderia a uma "verdade absoluta", cuja própria existência está subrrogada à futura elucidação (FREGE, 2009).

Essa permanente subrrogação da existência (ou descoberta) da "verdade absoluta" às elucidações futuras reflete, de certo modo, o entendimento de Karl Popper (2008), para quem as verdades científicas são apenas conjecturas ainda não refutadas, pois, mesmo as chamadas "certezas atuais" não concedem garantia de continuarem como "certezas" em um momento futuro.

Conceitos ou conhecimentos tidos como verídicos em determinado momento da existência humana podem posteriormente ser revelados como conceitos ou conhecimentos falsos, por esse motivo diz-se que a própria existência da "verdade absoluta" está sempre subrrogada à futura elucidação.

Ocorre que a norma jurídica é o elemento fundamental sobre o qual se ergue a Ciência do Direito, assim como a arqué é o elemento fundamental da matéria. Pela mesma razão que os filósofos da natureza se preocuparam em conhecer qual seria o elemento primordial do seu objeto de estudo, os filósofos do Direito se interessam por conhecer o elemento primordial do ordenamento jurídico: a norma jurídica.

Em meio a essa permanente busca pela "verdade absoluta", diversas concepções foram propostas visando à compreensão do fenômeno jurídico-normativo, de modo que o conceito de norma jurídica 
também teve variações ao longo da história, conforme o que fora aceito, em cada época, como sua "verdade atual".

\section{0 conceito de norma jurídica}

A moderna Ciência do Direito concebe a norma jurídica como forma preenchida por um conteúdo, de modo que seja um enunciador (forma) do direito natural (conteúdo). Em seu aspecto formal, a norma jurídica é uma proposição lógica, e, apenas nesse aspecto, vazia de conteúdo. Este fará parte do seu aspecto material, que se refere à necessária veiculação do direito natural por meio da norma (VASCONCELOS, 2006).

Essa diferenciação entre forma e conteúdo é um dos fundamentos da chamada teoria lógico-semântica da norma jurídica, fundada por Lourival Vilanova (1997) e desenvolvida por Paulo de Barros Carvalho (2015). Segundo essa concepção, a norma jurídica revela-se uma estrutura lógica (forma) aliada a um fundamento semântico, que lhe exprime um conteúdo (matéria).

Nem sempre, porém, houve atenção por parte dos juristas à relação entre forma e conteúdo na estruturação da norma. Durante muito tempo, a Ciência do Direito atribuiu à norma jurídica um conceito meramente "formal", teoria essa que teve especial acolhimento em Hans Kelsen (1998). Em sua tentativa de extrair da Ciência Jurídica quaisquer interferências exteriores, Kelsen esvaziou-lhe qualquer conteúdo valorativo, de modo que o Direito consistiria unicamente em uma forma a ser preenchida como bem entendesse (CARVALHO, 2009).

Feita essa ressalva quanto à complementaridade entre forma e conteúdo da norma jurídica, em virtude do objetivo deste trabalho, o estudo será, deste momento em diante, direcionado ao aspecto formal da norma jurídica, pois é neste que reside sua estrutura lógicoproposicional, a qual será destrinchada e examinada em seus aspectos específicos. 
A identificação da estrutura lógico-formal da norma jurídica, que seria aquela sobrelinguagem (ou metalinguagem) que veicularia e enunciaria seu conteúdo de direito, foi bem desenvolvida em Hans Kelsen (1986) e Carlos Cossio (1964). A evolução do pensamento desses autores será desvelada na sequência, na ordem exposta.

Ao estudar a estrutura lógico-formal da norma jurídica, Hans Kelsen (1986) a identificou como se fora um juízo hipotético-condicional, segundo o qual, na norma, se identificariam dois elementos: uma hipótese prevista e uma consequência prescrita. A relação lógica entre ambos os elementos, segundo Kelsen, é regida pelo operador lógico condicional, que, conforme exposto oportunamente, exprime um vínculo de implicação entre o elemento hipotético e a consequência, de modo que, uma vez ocorrida aquela, esta também o é: dada determinada hipótese, deve ser uma consequência.

Esse juízo hipotético-condicional exprime um dever-ser, segundo o qual, dada uma hipótese específica, deve ser uma consequência respectiva, ambos os elementos pré-determinados na norma. Ocorre que, por estipular um dever-ser (uma norma deôntica), esse juízo hipotético-condicional necessita de uma garantia da sua validade e da respeitabilidade de seus efeitos. Para tanto, há outro juízo, também hipotético-condicional, que elenca, como sua hipótese, não a conduta (consequência) originariamente desejada, mas sim sua eventual violação, ao que estabelece uma consequência sancionatória.

Ocorre que, para Kelsen, o cerne da norma jurídica é não a conduta pretendida, mas a sanção pelo seu descumprimento. $\mathrm{O}$ autor não apenas albergou o ilícito ao Direito, mas lhe conferiu um lugar de destaque ao se referir à norma sancionatória como verdadeira "norma primária", ao passo que a norma que estipularia a conduta desejada seria meramente uma "norma secundária".

A concepção de Kelsen, por isso mesmo bastante criticada, restou formulada na seguinte configuração: caso não ocorra a consequência $\mathrm{C}$, deve ser a sanção $\mathrm{S}$ (norma primária); dada hipótese $\mathrm{H}$, deve ser a consequência $\mathrm{C}$ (norma secundária). 
A consequência prática está em que o Direito, para Kelsen, orbita em torno do ilícito, o que não é de modo algum uma conduta antijurídica, já que, ao contrário, esse ilícito é o pressuposto hipotético da medida sancionatória, a norma primária.

Na formulação ora exposta, segundo Kelsen, cada modal deôntico (de dever-ser) configura uma norma, primária ou secundária, de modo que a união de ambas estrutura o que chamou de "norma complexa" ou "norma dupla".

Ao contrário de Kelsen, Carlos Cossio (1964) concebeu a norma jurídica não como um juízo hipotético-condicional, mas sim como um juízo disjuntivo. Sabe-se que, dentre os juízos disjuntivos, há o inclusivo e o exclusivo, como foi demonstrado oportunamente. A diferença entre ambos, rememore-se, reside em que o juízo disjuntivo inclusivo admite a ocorrência simultânea de ambas as proposições, como na comunicação: "um ou outro ou ambos", ao passo em que o juízo disjuntivo exclusivo não o admite: "apenas um ou outro, mas jamais ambos".

A norma jurídica, para a teoria egológica do Direito, é um juízo disjuntivo inclusivo (embora seu fundador, Carlos Cossio, não se pronuncie a respeito), pela razão que será exposta após necessárias considerações sobre sua teoria.

A forma lógica da norma como juízo disjuntivo, para Cossio, não é outra senão a seguinte: dada hipótese $\mathrm{H}$, deve ser a consequência C, ou, dado o não cumprimento da consequência $C$, deve ser a sanção S. Nessa concepção, o cerne da norma passa a ser o modal disjuntivo ("ou...") que une dois juízos hipotéticos ("deve ser"), não mais os operadores deônticos isoladamente.

Ao se recortar a norma completa exatamente em seu disjuntor, tem-se o que Cossio denominou endonorma e perinorma. A última é o juízo hipotético-condicional sancionador, um verdadeiro suporte à endonorma, que, a seu turno, seria a hipótese condicionante da conduta desejada, dentro da normalidade. 
À diferença de Kelsen, que atribuiu primariedade à norma sancionadora, Cossio apenas a concebeu como suporte (perinorma) à conduta desejada, de modo que o cerne da norma deve ser não a sanção, ou a força (em sua concepção), mas sim a conduta pretendida dentro da normalidade. A sanção que, para Kelsen, é o cerne do Direito, para Cossio, passa a ser mero suporte à endonorma, mas ambos ainda a concebem no sentido meramente coativo.

Uma vez sedimentada essa concepção, pode-se demonstrar por que a norma jurídica, na teoria egológica do Direito, de Carlos Cossio, é um juízo disjuntivo inclusivo e não exclusivo. É que a norma jurídica exprime uma consequência $\mathrm{C}$ a uma hipótese $\mathrm{H}$. No caso de não cumprimento dessa consequência $C$, se lhe impõe a sanção $S$.

Entender a norma como um juízo disjuntivo exclusivo é aceitar o fato de que a consequência da perinorma (a sanção) não pode coexistir com a consequência da endonorma (a conduta), porque o juízo disjuntivo exclusivo não admite a validade de ambas as proposições simultaneamente. Dessa forma, à ocorrência da sanção (perinorma), estaria impossibilitada a ocorrência também da conduta desejada (endonorma).

Um exemplo prático pode elucidar a questão: em uma relação jurídica tributária, caso o sujeito passivo não pague o tributo devido (previsto na endonorma), incidirá uma norma sancionadora punitiva, que veiculará uma multa (prevista na perinorma). A incidência da sanção da perinorma, no entanto, não impede a incidência também da endonorma. Desse modo, a multa pelo inadimplemento do crédito tributário (perinorma) não exime o sujeito passivo do pagamento também do tributo (endonorma), que ainda será devido (MACHADO, 2015).

Outro exemplo, também oriundo do Direito Tributário, é a respeito do descumprimento de uma obrigação tributária acessória (obrigação de fazer ou não fazer algo). É que o inadimplemento da obrigação tributária acessória, por exemplo, a de realizar declarações ou escriturações, provocaria o surgimento de uma obrigação tributária principal (obrigação de pagar) referente à multa. Ocorre que a multa (perinorma) não exime 
o sujeito passivo de realizar a declaração ou escrituração (endonorma), ao que ambas as exigências ocorrerão em conjunto (MACHADO, 2015).

Isso ocorre porque a norma jurídica é um juízo disjuntivo inclusivo, uma vez que a exigência da perinorma não exclui a exigência da endonorma. Do contrário, se fosse um juízo disjuntivo exclusivo, nos exemplos acima expostos, a multa pelo inadimplemento do crédito tributário dispensaria o sujeito passivo do recolhimento do tributo devido, e a obrigação tributária principal substituiria a acessória. Não apenas nesses exemplos, mas também em todos os demais, a perinorma e a endonorma seriam mutuamente excludentes, caso se entendesse a norma como um juízo disjuntivo exclusivo.

\section{0 problema da sanção premial}

Em meio às naturais dificuldades linguísticas e terminológicas referentes aos vários significados que uma palavra pode conotar, a pluralidade semântica do termo sanção adquire central importância para este estudo.

O vocábulo sanção adquire diversos significados na ciência jurídica, como adverte Paulo de Barros Carvalho (2013). Dentre outras acepções semânticas, pode significar: a) a penalidade decorrente de infração; b) o ato jurídico-administrativo que encerra o processo de elaboração de certas leis; ou c) a consequência prescrita na perinorma (ou norma primária).

No primeiro caso narrado, a palavra sanção atua como sinônimo de penalidade. É esta acepção que utiliza, por exemplo, o Código Tributário Nacional (CTN), em seu art. $3^{\circ}$, ao afirmar que o tributo não se confunde com a sanção (penalidade) por ato ilícito (MACHADO, 2014). No segundo caso, sanção significa o ato jurídico-administrativo no qual o chefe do Poder Executivo corrobora determinada lei, podendo vir a encerrar o processo legislativo ou, no caso de veto, devolver o projeto à casa legislativa respectiva para que tente superar o ato contrário. Neste 
caso, a palavra sanção é utilizada como antônimo de "veto", ao referirse ao final do processo legislativo.

Deter-se-á na terceira possibilidade semântica por maior tempo, pois esse uso do vocábulo sanção é o de maior importância para o objeto deste estudo, e é neste sentido que aqui será utilizado. Sanção pode se referir não à punição por ato ilícito nem ao ato referente ao processo legislativo, mas sim à consequência prescrita na perinorma. Isso quer dizer que sanção, no sentido que Ihe dá a teoria geral do Direito, é o elemento da perinorma que prescreve uma consequência em virtude do não cumprimento dos exatos termos de uma conduta prescrita na endonorma.

Segundo a teoria egológica, de Cossio (1964), a norma completa (norma complexa ou norma dupla) consiste em dois juízos hipotéticoscondicionais conectados por um juízo disjuntivo. É dizer: a norma completa consiste em duas expressões de dever-ser em que pode incidir qualquer uma das duas isoladamente ou ambas simultaneamente: deve ser a conduta desejada ou deve ser a sanção ou ambas.

$\mathrm{Na}$ expressão formal da norma completa, a sanção aparece como o resultado pelo não cumprimento da consequência prescrita na endonorma (norma secundária, segundo Kelsen). Esse conceito nada diz quanto ao conteúdo em si veiculado na sanção.

O impasse reside no fato de que muitos juristas ignoram o conceito de sanção como consequência da perinorma e apenas o empregam como sinônimo de penalidade. A consequência de se aceitar essa presunção é que a norma jurídica (e o Direito) consistiria eminentemente em uma ameaça permanente aos destinatários, coagindo-lhes de forma incessante para assegurar a respeitabilidade do ordenamento.

$\mathrm{Na}$ modernidade, esse problema da tentativa de incursão da força e da coação na essência do Direito remonta a Immanuel Kant, e foi fortalecido por lhering e Kelsen. Tanto no âmago dos cientistas do Direito como no imaginário de outros estudiosos não juristas, como Jürgen Habermas e Paul Ricoeur, o equívoco se confirma. Conforme 
aponta Arnaldo Vasconcelos (2001), o erro fundamental cometido por todos esses autores foi o de confundir Direito com Estado.

De fato, há na Ciência Política o clássico conceito de Max Weber (2003, p. 19), segundo o qual o Estado "conseguiu o monopólio do uso legítimo da força física como meio de dominação nos limites de um território". Segundo essa concepção, o Estado seria, assim, o ente com monopólio do uso da coação. Ainda que se aceite essa concepção, transcendê-la do Estado para o Direito, como se houvesse identidade entre ambos, seria ainda um erro crucial.

Identificar o Estado com o Direito, como se este não existisse fora daquele, é ignorar, completamente, tanto a existência do Direito natural como a ocorrência de normas e de regimes jurídicos privados, como foi o contratualismo durante boa parte da Era Feudal (SALDANHA, 2005).

Resulta descabido o argumento de que o Direito seria, em sua essência, coativo. Em virtude da especificidade da essência do ser, não se pode cogitar que um atributo meramente eventual, que pode ou não ocorrer, constituísse a essência. Não se pode fazê-lo porque, no momento em que essa eventualidade deixasse de ocorrer, a essência desapareceria e, sem ela, o "ser" simplesmente deixaria de ser. Cogitar nessa possibilidade é simplesmente realizar um verdadeiro malabarismo metafísico para adequar as propriedades da essência ao mero dissabor dos desejos e da imaginação pessoais.

Aquilo que compõe a essência é, por definição, uno, imutável, permanente. Jamais poderia a essência padecer de eventualidade conforme as variáveis do mundo fenomênico, sendo essa mais uma verificação da já mencionada incapacidade de os conteúdos afetarem as formas.

Dessa maneira, a essência do Direito é aquilo que lhe é enquanto é. Se houver alguma possibilidade, ainda que ínfima, de haver Direito sem coação, não pode pertencer à essência, mas apenas pode se revelar como um aspecto de sua existência. Indaga, de forma retórica, Goffredo Telles Júnior (2008, p. 91): "Se a norma jurídica for definida por meio da 
coação, seria natural perguntar em que consiste a norma jurídica antes da violação dela". Se o Direito fosse sempre coativo, somente haveria direito após a violação da norma jurídica.

Percebem-se dois equívocos comuns à doutrina jurídica: primeiro, que a coação não faz parte da essência do Direito; segundo, que a coação não se confunde com a sanção. Ao passo que a coação é, na verdade, mero instrumento acidental do Direito, a sanção é um elemento da estrutura lógico-formal da norma jurídica, é precisamente a consequência da perinorma.

A sanção serve de mero veículo incidental para o caso de não cumprimento da conduta ideal prescrita na endonorma em seus exatos termos. Esse veículo pode desembocar na autorização para que se proceda à coação, como último recurso. Mas pode também não fazê-lo, como sói ocorrer muitas vezes.

A sanção, como elemento da perinorma na estrutura lógicoformal da norma jurídica, é apenas um casulo que pode ser preenchido com determinações diversas. O que se chama sanção é apenas uma consequência de um dos juízos hipotético-condicionais que formam o juízo disjuntivo da norma. Como forma, a sanção pode ser preenchida por conteúdos diversos. Será dita sanção punitiva se, no caso concreto, a sanção for uma consequência negativa por uma conduta a menor da desejável, ou será dita sanção premial se, no caso concreto, a sanção for uma consequência positiva por uma conduta a maior da desejável, sobrecomum.

Sendo a sanção pertencente ao mundo das formas lógicas, seu conteúdo prescritivo, quer seja ele positivo, quer negativo, premial ou punitivo, não lhe afetará em sua natureza. A essência da sanção está precisamente em ser a consequência prescrita na perinorma, e essa essência não é influenciada pelo conteúdo que lhe preencherá, como forma que é. Logo, seja esse conteúdo punitivo ou premial, a sanção continuará a ser o que é, pois sua essência formal não é afetada pelas variáveis do mundo das coisas que existem. 
Por essa razão, não se pode concordar com o entendimento de Hugo de Brito Machado (2014, p. 351), para quem apenas a sanção punitiva pertenceria ao consequente da perinorma, ao passo que a sanção premial seria, na verdade, o consequente de outra endonorma diversa e autônoma: "O prêmio, na verdade, não é sanção, mas simplesmente uma prestação integrante da estrutura de outra norma $[\ldots]$..

Essa diferença no tratamento lógico-formal entre uma sanção punitiva e uma sanção premial, na estrutura da norma jurídica, fundamentada apenas no conteúdo da sanção, não pode prosperar. Isso porque, dada a estrutura formal da norma jurídica, apenas sob o ponto de vista formal é que se poderia realizar alguma distinção, jamais com base em seu conteúdo.

Pela mesma razão que a existência não afeta a essência, o conteúdo punitivo ou premial da sanção não pode afetar sua forma lógica. Os critérios balizadores de uma aproximação ou de um distanciamento entre elementos endonormativos ou perinormativos das normas jurídicas devem ser feitos sempre com base em critérios lógico-formais, nunca com base em seu conteúdo.

\section{Um problema de lógica jurídica formal}

Todas as dificuldades que permeiam a discussão sobre o espaço da sanção premial na estrutura lógica da norma jurídica decorrem de certo desconhecimento, por parte de alguns juristas, da própria lógica formal. Nesse sentido, os problemas suscitados revelam-se apenas pseudoproblemas, aparentemente oriundos de uma verdadeira confusão original.

Desde que se fez menção aos operadores lógicos, utiliza-se reiteradamente o primeiro deles, o operador da negação (representado por “ ” ou “ $\neg$ ”, nos exemplos que seguiram, sendo em todos utilizado propositalmente para representar o não cumprimento da prestação devida (não cumprimento da consequência ou conduta). 
Foi exposto alhures que esse operador lógico da negação " " inverte o sentido do signo que lhe segue, de modo que o signo " $C$ ", por exemplo, acrescido o operador da negação " " torna-se "não C". Enquanto a proposição "C" elege uma possibilidade em um universo e exclui as demais, sua negação ofusca essa possibilidade, mas autoriza todas as demais.

A lógica formal é bivalente, quer dizer, os valores que podem ser assumidos por seus signos são de apenas duas ordens: verdadeiro ou falso; válido ou inválido. A consequência prática dessa constatação é que, sendo o signo "C" de qualquer um desses valores, o seu oposto " C C" será necessariamente do outro valor. Caso "C" seja verdadeiro ou válido, " C" será necessariamente falso ou inválido.

A seguir por esta linha de raciocínio, constatar-se-á que, admitindo "C" como "C" (C é igual a $C$ ), conclui-se que a negação " C" não poderá ser C ( C não é igual a $C$ ) por motivos óbvios. Esse é o oitavo axioma de Gottlob Frege (1972), o axioma da identidade. Pelo menos no mundo das formas, da metafísica, alheio às contradições do mundo físico, o ser "C" não pode ser e não ser ao mesmo tempo. É ou não é, mas jamais ambos.

Esse pressuposto é de fácil constatação, porém esconde uma particularidade obscura à primeira análise. $O$ fato de " $C$ " não ser $C$ apenas quer dizer que ambos são diferentes. Um não pode ser o que o outro é, mas pode ser qualquer coisa que o outro não seja. Com a devida licença de Parmênides, pode-se concluir que o "C" é "C" e não pode ser "não C"; e o "não C" não é nem pode ser "C".

Se "C" for igual a "realizar determinada conduta nos exatos ditames da endonorma", " C C" ("não C") consistirá no universo de todas as outras possibilidades que não configurem a realização de "determinada conduta nos exatos ditames da endonorma". Dentro desse universo, estão as seguintes possibilidades: a) não realizar nada; b) realizar parcialmente, aquém dos ditames; ou c) realizar completamente e além dos ditames. Nenhuma dessas três possibilidades expostas coincide com a definição de "C" como "determinada conduta nos exatos ditames da endonorma". 
O nada, o aquém e o além são todos possibilidades do " C", porque nenhum deles é "C". Essa relação apenas pode ocorrer diante do que Ihe é extrínseco: aquilo que está acima ou abaixo do Sol não pode ser o próprio Sol. Há de se comparar com algo exterior. Há esse vício condicionado na mentalidade jurídica de que o " C ", o não cumprimento de uma consequência em seus exatos ditames, somente poderia significar o seu absoluto descumprimento ou seu cumprimento parcial insuficiente, ao que acaba por ignorar a possibilidade de cumprimento além do esperado, de cumprimento sobrecomum, que também está incluída no universo de " C".

Dessas possibilidades, caberá à própria norma delimitar quais the serão juridicamente relevantes. A norma pode conferir ao cumprimento parcial aquém o mesmo tratamento conferido ao descumprimento absoluto, assim como pode dar ao cumprimento integral além do esperado o mesmo tratamento dado ao cumprimento nos exatos termos.

Pode fazê-lo, mas também pode fazer diferente. É possível, e não raro, que a norma crie distinções no grau de cumprimento de sua conduta pretendida, e pode, inclusive, estipular retribuições e benefícios ao protagonista de condutas sobrecomuns, além do "normal".

A conclusão não pode ser outra senão a seguinte, ainda que se assuma o risco de incidir em pleonasmo: o "não C" não é "C". O "não C" é diferente de "C": se "C" = "C", então "não C" $\neq$ "C". Caso se compreenda "C" como uma conduta especificada em exatos termos, então todas aquelas condutas fora desses exatos termos estão excluídas do conceito de "C". São todas "não C", portanto.

Elucide a questão com o seguinte exemplo: João buscava comprar um livro de Gabriel, que lhe cobra vinte dinheiros para tanto. Tem-se a seguinte formulação: dada a compra do livro, João deve pagar a Gabriel vinte dinheiros. Esta é a endonorma do exemplo. Se João pagar os vinte dinheiros a Gabriel, encerra aí qualquer discussão. Em outros termos, se João cumprir exatamente o que se espera na consequência da endonorma (pagar vinte dinheiros), está satisfeita a relação jurídica. 
Ocorre que João pode não pagar vinte dinheiros. Essa divergência acarreta na incidência da perinorma, a veicular a sanção. Dizer que João não pagou vinte dinheiros não revela muita coisa. Se não pagou vinte dinheiros, quanto pagou? Zero, dez, trinta, cinquenta? Pode ter pago apenas quinze dinheiros (aquém do esperado na endonorma), ao que incidirá contra si sanção punitiva para que pague o restante. Pode ter pago, entretanto, cinquenta dinheiros (além do esperado da endonorma), ao que incidirá a seu favor a sanção premial para que receba o troco devido em virtude de ter pago além do preço cobrado.

Desse fértil exemplo, percebe-se de forma clara o que se expõe. Se a conduta estipulada na endonorma é o "pagamento de vinte dinheiros" (esta conduta considerada como "C"), tanto no caso de pagamento de quantia menor que a esperada como no caso de pagamento de quantia maior, não ocorre o "pagamento de vinte dinheiros". Portanto, pagar quinze ou cinquenta dinheiros são ambos casos de " $\sim$ ", porque os dois são diferentes da conduta desejada, cada um a seu modo $(15 \neq 20 \neq 50)$.

A conduta sobrecomum de pagar acima do valor cobrado está logicamente excluída do universo de possibilidades de "C". Caso estivesse incluída em " $C$ ", o pagamento a mais teria o mesmo efeito do pagamento do valor exato, de modo que encerraria a relação jurídica sem qualquer outra consequência, pois apenas as hipóteses de " C" fazem incidir a perinorma.

Desconsiderar a prestação a mais (sobrecomum) do universo de possibilidades do "não C" seria negar a João o direito de ter seu troco restituído após ter realizado a Gabriel um pagamento em valor superior ao cobrado pelo livro.

Na seguinte norma: dada a hipótese $\mathrm{H}$, deve ser a conduta $\mathrm{C}$, ou, dado o não cumprimento da conduta $C$, deve ser a sanção $S$; apenas as condutas que se enquadrem, em precisos termos, no conceito de "C" são capazes de satisfazer a endonorma e encerrar a relação. Qualquer outra conduta diferente de " $\mathrm{C}$ ", desde que prevista em " C", dará continuidade à relação ao provocar a incidência da respectiva norma sancionatória, quer seja destinada a conferir um prêmio ou penalidade. As respectivas 
condições que direcionem a um ou outro estarão elencadas na própria norma.

O elemento determinante, portanto, é a própria norma, que delimita em sua endonorma o fato individualizado no espaço e no tempo, relevante para a incidência jurídica, bem como os exatos termos da consequência prescrita. Ao elucidar esse problema, torna-se simples identificar, na estrutura lógico-formal da norma jurídica, tanto o lugar da sanção punitiva como o da sanção premial. Leia-se, mais uma vez: dada determinada hipótese $\mathrm{H}$, deve ser uma conduta $\mathrm{C}$ em seus exatos termos ou, dada não ocorrência da conduta $\mathrm{C}$ em seus exatos termos (diferente de $\mathrm{C}$ ), deve ser a sanção respectiva.

A norma completa, com inclusão da possibilidade de incidência da sanção premial, deve ser lida da seguinte forma: "dada a hipótese $\mathrm{H}$, deve ser a conduta $\mathrm{C}$ em seus exatos termos, ou, caso não haja a conduta $C$ em seus exatos termos, deve ser a sanção $S$ de modo que, caso a prestação tenha sido menor que a conduta desejada, deve ser a sanção punitiva $S^{1}$, ou, caso a prestação seja maior que a conduta desejada, deve ser a sanção premial $S^{2}$, mas não ambas". Para fins de melhor compreensão, essa estrutura será destrinchada para estudo de cada aspecto, isoladamente.

Para facilitar o estudo, identifica-se a endonorma "dada a hipótese $\mathrm{H}$, deve ser a conduta $\mathrm{C}$ em seus exatos termos" e a perinorma "caso não haja a conduta $C$ em seus exatos termos, deve ser a sanção $S$ ", unidas pela disjunção "ou”, tal como preconizara Carlos Cossio (1964). Nenhuma dificuldade nesse aspecto, uma vez que essa estrutura já se tornou conhecida por diversos trabalhos nacionais de teoria geral do Direito e de teoria da norma jurídica.

O restante da norma, que abrange as sanções punitiva e premial, merece melhor explanação. É a seguinte estrutura: "caso a prestação tenha sido menor que a conduta desejada, deve ser a sanção punitiva $\mathrm{S}^{1}$, ou, caso a prestação seja maior que a conduta desejada, deve ser a sanção premial $\mathrm{S}^{2}$, mas não ambas". Trata-se de um juízo disjuntivo exclusivo que separa as sanções punitiva e premial. É um juízo disjuntivo 
exclusivo, porque, como já diversas vezes abordado, esse juízo implica a possibilidade de ocorrência de qualquer uma das duas situações postas, mas veda sua ocorrência simultânea, já que seria descabido cogitar uma conduta que fosse, ao mesmo tempo, aquém e além da conduta esperada na endonorma, de modo a fazer incidir simultaneamente uma punição e um prêmio pela mesma conduta.

Esse juízo disjuntivo exclusivo relaciona dois juízos hipotéticocondicionais. À esquerda dessa disjunção, tem-se a sanção punitiva $\mathrm{S}^{1}$, reservada às condutas a menor do esperado. Se a conduta praticada for um cumprimento apenas parcial ou mesmo o total descumprimento da conduta esperada, deverá incidir a sanção punitiva, já que a conduta ficou aquém da conduta desejável estabelecida pela endonorma.

A derradeira fração dessa estrutura a ser estudada é a que fica à direita do juízo disjuntivo exclusivo, situação reservada às condutas sobrecomuns, além do esperado. Se a conduta que divergiu de "C" diferenciou-se por ter ido além da conduta desejável estabelecida pela endonorma, fará incidir a sanção premial, desde que a norma comporte o reconhecimento dessa situação.

A leitura da norma completa, incluindo a especificidade do tipo de sanção nela veiculado, é feita da seguinte forma: dada uma hipótese $H$, deve ser uma conduta $\mathrm{C}$ em seus exatos termos ou, dada não ocorrência de $C$ em seus exatos termos, deve ser uma sanção $S$ de modo que, se a prestação foi menor que $C$, deve ser a sanção punitiva $S^{1}$, ou, se a conduta foi maior que $\mathrm{C}$, deve ser a sanção premial $\mathrm{S}^{2}$.

É essa a correta estrutura lógico-formal da norma jurídica que abarca ambos os tipos de sanção, seja ela punitiva $\left(\mathrm{S}^{1}\right)$ pelo cumprimento apenas parcial da conduta ou pelo seu descumprimento absoluto, seja ela premial $\left(S^{2}\right)$, pelo cumprimento sobrecomum, além dos termos estipulados na endonorma. 


\section{Conclusão}

Pode-se concluir seguramente que a coação não pode fazer parte da essência do Direito, já que é possível, e não raro, haver relações jurídicas que não nascem, não se desenvolvem e não se exaurem por incidência de uma força física, nem se dão sob a égide perene de uma ameaça constante.

Pela constatação de haver pelo menos uma relação jurídica, cuja existência se dê à revelia da coação, percebe-se logicamente que essa coação não pode pertencer ao plano metafísico da essência, e sim ao plano físico da existência.

A essência é a unidade do ser enquanto tal, sempre verificável. A existência, ao contrário, é incidental, é plural. Cogitar em um direito essencialmente coativo seria negar a juridicidade de qualquer relação jurídica que existisse alheia à imposição pela força física, como é o caso da sanção premial.

Precisamente porque a coação pode ou não se encontrar na relação jurídica, torna-se impossível que seja pertencente à essência. Há ou não há coação, porque existe ou não existe imposição pela força física. Essa proposição confirma o teor existencial da coação jurídica como mero incidente no desenvolvimento lógico da norma. É alheia, portanto, à essência do Direito.

Para se aprofundar na percepção da estrutura formal da norma jurídica, foi necessário utilizar a linguagem normativa como base para lançamento cognitivo em direção à metafísica. É que, conforme foi demonstrado, toda linguagem possui na essência uma estrutura metafísica lógico-formal. Para conhecer essa estrutura, é preciso despir a linguagem de seu conteúdo, e tudo o que restará será a forma, a linguagem formalizada a que se denominou sobrelinguagem.

Ao aprofundar o estudo na estrutura formal da norma, foi demonstrado que a coação é apenas um incidente na relação jurídica, um mecanismo para assegurar a respeitabilidade da incidência da 
norma veiculada pela sanção. Esse veículo, prescrito na perinorma, por sua vez, é uma estrutura lógico-formal, metafísica, cujo conteúdo variável pode indicar a uma coação, a fim de punir uma conduta aquém do ideal prescrito na endonorma, ou a um prêmio, a fim de retribuir uma conduta além do ideal prescrito na endonorma.

Ante todo o substrato teórico considerado, pôde-se demonstrar que a conduta ideal prescrita na endonorma pode ser cumprida em seus exatos termos prescritos, bem como pode haver cumprimento aquém desses termos, o que acarretará a incidência da sanção punitiva, ou cumprimento além desses termos, o que acarretará a incidência da sanção premial. Ambos os tipos de sanção estão localizados no mesmo plano lógico-formal e, como consequente, prescrito na perinorma, e divergem entre si apenas quanto ao seu conteúdo punitivo ou premial.

\section{Referências}

ALVES, Alaôr Caffé. Lógica: pensamento formal e argumentação. 4. ed. São Paulo: Quartier Latin, 2005.

CARVALHO, Paulo de Barros. Direito tributário: fundamentos jurídicos da incidência. 10. ed. São Paulo: Saraiva, 2015.

. Direito tributário: linguagem e método. 5. ed. São Paulo: Noeses, 2013.

Teoria da norma tributária. 5. ed. São Paulo: Quartier Latin, 2009.

COSSIO, Carlos. La teoría egológica del derecho y el concepto jurídico de libertad. 2. ed. Buenos Aires: Abeledo-Perrot, 1964.

COSTA, Adriano Soares da. Teoria da incidência da norma jurídica: crítica ao realismo linguístico de Paulo de Barros Carvalho. 2. ed. São Paulo: Malheiros, 2009.

FREGE, Gottlob. Conceptografía: los fundamentos jurídicos de la aritmética y otros estudios filosóficos. Traducción Hugo Padilla. Ciudad de México: Universidad Nacional Autónoma de México, 1972. 
. Lógica e filosofia da linguagem. 2. ed. São Paulo: Editora da Universidade de São Paulo, 2009.

KANT, Immanuel. Crítica da razão pura. 5. ed. Lisboa: Fundação Calouste Gulbenkian, 2001.

KELSEN, Hans. Teoria geral das normas. Porto Alegre: Fabris: 1986. . Teoria geral do direito e do Estado. 3. ed. São Paulo: Martins Fontes, 1998.

MACHADO, Hugo de Brito. A denominada sanção premial no âmbito do direito tributário. In: MENEZES, Joyceane Bezerra de (Org.). Teoria do direito em debate: estudos em homenagem ao professor Arnaldo Vasconcelos. Florianópolis: Conceito Editorial, 2014.

. Curso de direito tributário. 36. ed. São Paulo: Malheiros, 2015.

MAGALHÃES FILHO, Glauco Barreira. Curso de hermenêutica jurídica. 5. ed. São Paulo: Atlas, 2015.

POPPER, Karl. A lógica da pesquisa científica. 16. ed. São Paulo: Cultrix, 2008.

ROSS, Alf. Direito e justiça. Tradução Edson Bini. Bauru: Edipro, 2000.

SALDANHA, Nelson. 0 jardim e a praça: o privado e o público na vida social e histórica. 2. ed. Rio de Janeiro: Atlântica Editora, 2005.

SANTOS, Mário Ferreira dos. Teoria do conhecimento: gnoseologia e criteriologia. São Paulo: Logos, 1958.

TELLES JÚNIOR, Goffredo. Iniciação na ciência do direito. 4. ed. São Paulo: Saraiva, 2008.

VASCONCELOS, Arnaldo. Direito e força: uma visão pluridimensional da coação jurídica. São Paulo: Dialética, 2001.

. Teoria da norma jurídica. 6. ed. São Paulo: Malheiros, 2006.

VILANOVA, Lourival. As estruturas lógicas e o sistema do direito positivo. São Paulo: Max Limonad, 1997. 
WEBER, Max. A política como vocação. Brasília: Editora da Universidade de Brasília, 2003.

WITTGENSTEIN, Ludwig. Tractatus logico-philosophicus. São Paulo: Companhia Editora Nacional, 1968.

ZUBIRI, Xavier. Inteligência e realidade. Tradução Carlos Nougué. São Paulo: É Realizações, 2011.

Recebido em: 07/04/2016 Aprovado em: 14/03/2017 